\title{
Reaction kinetic analysis of reactor surveillance data
}

\author{
$\operatorname{AUTHOR}(\mathrm{S})$ :
}

Yoshiie, T.; Sato, K.; Xu, Q.; Nagai, Y.

\section{CITATION:}

Yoshiie, T.... [et al]. Reaction kinetic analysis of reactor surveillance data. Nuclear Instruments and Methods in Physics Research Section B: Beam Interactions with Materials and Atoms 2015, 352: 125-129

\section{ISSUE DATE:}

2015-06

URL:

http://hdl.handle.net/2433/202061

\section{RIGHT:}

(c) 2015. This manuscript version is made available under the CC-BY-NC-ND 4.0 license

http://creativecommons.org/licenses/by-nc-nd/4.0/; The full-text file will be made open to the public on 30 January 2017 in accordance with publisher's 'Terms and Conditions for Self-Archiving'.; This is not the published version. Please cite only the published version.; この論文は出版社版でありません。引用の際には出版社版をご確認ご利用ください。 


\title{
Reaction Kinetic Analysis of Reactor Surveillance Data
}

\author{
T. Yoshiie ${ }^{\mathrm{a}}$, K. Sato ${ }^{\mathrm{a}}, \mathrm{Q} . \mathrm{Xu}^{\mathrm{a}}$, Y. Nagai ${ }^{\mathrm{b}}$ \\ aResearch Reactor Institute, Kyoto University, Kumatori-cho, Sennan-gun, Osaka-fu 590-0494, Japan \\ ${ }^{\mathrm{b}}$ The Oarai Center, Institute for Materials Research, Tohoku University, Oarai, Ibaraki 311-1313, Japan
}

\begin{abstract}
In reactor pressure vessel surveillance data, it was found that the concentration of matrix defects was very low even after nearly 40 years of operation, though a large number of precipitates existed. In this paper, defect structures obtained from surveillance data of A533B (high $\mathrm{Cu}$ concentration) were simulated using reaction kinetic analysis with 11 rate equations. The coefficients used in the equations were quite different from those obtained by fitting a Fe- $0.6 \mathrm{wt} \% \mathrm{Cu}$ alloy irradiated by the Kyoto University Reactor. The difference was mainly caused by alloying elements in A533B, and the effect of alloying elements was extracted. The same code was applied to low-Cu A533B irradiated with high irradiation damage rate, and the formation of voids was correctly simulated.
\end{abstract}

\section{Introduction}

High-energy particle irradiation induces damage in solids and changes their properties. In particular, the degradation of mechanical properties of structural materials used in nuclear power plants is of critical importance. Neutron irradiation embrittlement of reactor pressure vessel steels is one of the principal aging issues. The number of reactors worldwide that have been in operation for about or more than 40 years is increasing. Surveillance data from these aged reactors indicate higher ductile brittle transition temperatures than those predicted by embrittlement correlation methods [1,2]. In particular, the precipitates are the main defect clusters, and only small quantities of loops were observed by transmission electron microscopy. No evidence of vacancy clusters was detected [3]. Table 1 shows an example of surveillance data of the Genkai Unit 1 from Kyushu Electric Power Co., Inc. [4,5]. This unit is a pressurized water reactor and the first unit is in operation since 1975. The pressure vessel is a low alloy steel A533B (Mn: 1.48, Ni: 0.56, Mo: 0.47, Si: 0.25, Cu: 0.12, P: 0.010, S: $0.014 \mathrm{wt} \%$ ). The nature of the loops was not mentioned, but it should be of interstitial type.

The defect structural evolution of pressure vessel model alloys (Fe-0.6 wt\%Cu), irradiated by Kyoto University Reactor (at $573 \mathrm{~K}$, with $1.5 \times 10^{-8} \mathrm{dpa} / \mathrm{s}$ ) were analyzed using reaction kinetic analysis [6]. Experimental results of defect structural evolution in $\mathrm{Fe}-0.6 \mathrm{wt} \% \mathrm{Cu}$ were correctly reproduced by simulations.

In this paper, the defect structural evolution obtained from surveillance data from the Genkai Unit 1 was simulated with the same code adopted in reference 6 . It was impossible, however, to simulate the evolution by changing only the damage rate and irradiation temperature, because the surveillance test pieces are made of A533B and contain a lot of alloying elements other than Fe-0.6 wt\%Cu. We therefore adjusted the coefficients of the rate equations to reproduce the surveillance data by introducing and analyzing effects due to alloying elements. The code was then applied for analyzing defect structures of low Cu A533B irradiated by the Japan Materials Testing Reactor (JMTR), with a damage rate of $3.3 \times 10^{-7} \mathrm{dpa} / \mathrm{s}$.

\section{Method}

The model used for the calculations is based on the rate theory and it was also used in a previous paper [6]. The model describes the reaction rates among point defects and their defect clusters [7]. The following assumptions were made in the calculation:

(1) The time dependence of 11 variables is calculated near 1 dpa for the following quantities: the concentration of interstitials, interstitial clusters (interstitial-type dislocation loops), vacancies, vacancy clusters in the matrix (voids), solutes, solute-vacancy pairs, solute-vacancy clusters, the total interstitials in interstitial type dislocation loops, the total vacancies in voids, the total vacancies in solute-vacancy clusters, and the total solute atoms in solute-vacancy clusters. The average cluster size is considered.

(2) Mobile defects are interstitials, vacancies, and solute-vacancy pairs.

(3) The thermal dissociation of vacancies is considered for solute-vacancy pairs, voids and vacancies in solute-vacancy clusters. After the dissociation of all vacancies, solute-vacancy clusters are considered as precipitates.

(4) Di-interstitials and di-vacancies are set for stable nuclei belonging to loops and voids, respectively [8,9]. 
(5) Vacancy + solute-vacancy pair, solute-vacancy pair + solute-vacancy pair, and solute + solute-vacancy pair are also set for stable nuclei of solute-vacancy clusters.

The concentrations of interstitials $\left(C_{I}\right)$, vacancies $\left(C_{V}\right)$, isolated solutes in the matrix $\left(C_{M}\right)$, and solute-vacancy pairs $\left(C_{V M}\right)$ are expressed as:

$$
\begin{aligned}
& \frac{d C_{I}}{d t}=P_{I}-2 Z_{I, I} M_{I} C_{I}^{2}-Z_{I, V}\left(M_{I}+M_{V}\right) C_{I} C_{V}-Z_{I, V M} M_{I} C_{I} C_{V M}-Z_{I, I C} M_{I} C_{I} S_{I C}-Z_{I, V C} M_{I} C_{I} S_{V C} \\
& -Z_{I, P C} M_{I} C_{I} S_{P C}-M_{I} C_{I} C_{S}-N_{I} P_{I C} \\
& \frac{d C_{V}}{d t}=P_{V}-2 Z_{V, V} M_{V} C_{V}^{2}-Z_{I, V}\left(M_{I}+M_{V}\right) C_{I} C_{V}-Z_{V, V M}\left(M_{V}+M_{V M}\right) C_{V} C_{V M}-Z_{V, V C} M_{V} C_{V} S_{V C}-Z_{V, I C} M_{V} C_{V} S_{I C} \\
& -Z_{V, P C} M_{V} C_{V} S_{P C}-Z_{V, M} M_{V} C_{V} C_{M}+B_{V, M} M_{V} C_{V M}+B_{V, P C} M_{V} S_{P C}+B_{V, V C} M_{V} S_{V C}-M_{V} C_{V} C_{S}-N_{V} P_{V C} \\
& \frac{d C_{M}}{d t}=Z_{I, V M} C_{I} C_{V M}+B_{V, V M} M_{V} C_{V M}-Z_{V M, M} M_{V M} C_{V M} C_{M}-Z_{V, M} M_{V} C_{V} C_{M} \\
& \frac{d C_{V M}}{d t}=-Z_{I, V M} C_{I} C_{V M}-Z_{V, V M}\left(M_{V}+M_{V M}\right) C_{V} C_{V M}-2 Z_{V M, V M} M_{V M} C_{V M} C_{V M}-Z_{V M, M} M_{V M} C_{V M} C_{M}-B_{V, V M} M_{V} C_{V M} \\
& -Z_{V M, I C} M_{V M} C_{V M} S_{I C}-Z_{V M, V C} M_{V M} C_{V M} S_{V C}-Z_{V M, P C} M_{V M} C_{V M} S_{P C}-M_{V M} C_{V M} C_{S},
\end{aligned}
$$

where $P$ is the production rate of point defects (damage rate) and $Z$ is the number of sites in the spontaneous reaction for each process. $M$ is the mobility of defects, and it is expressed as $v \exp \left(-\frac{E_{M}}{k T}\right)$, where $v$ is an effective frequency associated with the vibration of the defects in the direction of the saddle point, and it is taken as $10^{13} / \mathrm{s}$. $E, k$, and $T$ are the migration energy, the Boltzmann constant and the temperature, respectively. $N$ is the number of atoms in the clusters formed directly in cascade processes. $B$ is the dissociation probability of vacancies with solute-vacancy pairs, voids and solute-vacancy clusters, and it is expressed as $\exp \left(-\frac{K}{k T}\right)$, where $K$ is the binding energy. $K_{V, M}, K_{V, V C}$, and $K_{V, P C}$ are the binding energies between vacancies and solutes atoms, between vacancies and voids in the matrix, and between vacancies and solute-vacancy clusters, respectively. The subscripts $I, V, M, V M, P C, I C$, and $V C$ denote interstitials, vacancies, solutes, solute-vacancy pairs, solute-vacancy clusters, interstitial type dislocation loops and voids, respectively. The surfaces, grain boundaries, and pre-existing defects such as dislocations are expressed by the sink efficiency $C_{S}$. The concentrations are in fractional units. $S$ is the total sink efficiency of clusters $[8,9]$, expressed as

$$
\begin{aligned}
& S_{V C}=\left(48 \pi^{2} R_{V C} C_{V C}^{2}\right)^{1 / 3}, \\
& S_{I C}=2\left(\pi R_{I C} C_{I C}\right)^{1 / 2}, \\
& S_{P C}=\left(48 \pi^{2}\left(R_{P V}+R_{P M}\right) C_{P C}^{2}\right)^{1 / 3} .
\end{aligned}
$$

The nucleation rates of interstitial type dislocation loops (concentration: $\left.C_{I C}\right)$, voids $\left(C_{V C}\right)$, and solute-vacancy clusters $\left(C_{P C}\right)$ are:

$$
\begin{aligned}
& \frac{d C_{I C}}{d t}=P_{I C}+Z_{I, I} M_{I} C_{I}^{2}, \\
& \frac{d C_{V C}}{d t}=P_{V C}+Z_{V, V} M_{V} C_{V}{ }^{2}, \\
& \frac{d C_{P C}}{d t}=Z_{V, V M}\left(M_{V}+M_{V M}\right) C_{V} C_{V M}+Z_{V M, V M} C_{V M}{ }^{2}+Z_{V M, M} M_{V M} C_{V M} C_{M} .
\end{aligned}
$$

$P_{I C}$ and $P_{V C}$ are the production rates of interstitial type dislocation loops and voids directly from cascades, respectively.

The total accumulation of interstitials in loops $\left(R_{I C}\right)$, vacancies in voids from the matrix $\left(R_{V C}\right)$, and vacancies from solute-vacancy clusters $\left(R_{P V}\right)$ are, respectively, 


$$
\begin{aligned}
& \frac{d R_{I C}}{d t}=2 Z_{I, I} M_{I} C_{I}^{2}+Z_{I, I C} M_{I} C_{I} S_{I C}+Z_{V M, I C} M_{V M} C_{V M} S_{I C}-Z_{V, I C} M_{V} C_{V} S_{I C}+N_{I} P_{I C} \\
& \frac{d R_{V C}}{d t}=2 Z_{V, V} M_{V} C_{V}^{2}+Z_{I, V C} M_{V} C_{V} S_{V C}+Z_{V M, V C} M_{V M} C_{V M} S_{V C}-Z_{I, V C} M_{I} C_{I} S_{V C}-B_{V, V C} M_{V} S_{V C}+N_{V} P_{V C}, \\
& \frac{d R_{P V}}{d t}=2 Z_{V, V M}\left(M_{V}+M_{V M}\right) C_{V} C_{V M}+2 Z_{V M, V M} M_{V M} C_{V M}{ }^{2}+Z_{V M, M} M_{V M} C_{V M} C_{M}+Z_{V M, P C} M_{V M} C_{V M} S_{P C} \\
& -Z_{I, P C} M_{I} C_{I} S_{P C}+Z_{V, P C} M_{V} C_{V} S_{P C}-B_{V, P C} M_{V} S_{P C} .
\end{aligned}
$$

The total accumulation of solutes in solute-vacancy clusters $\left(R_{P M}\right)$ is

$$
\frac{d R_{P M}}{d t}=Z_{V, V M}\left(M_{V}+M_{V M}\right) C_{V} C_{V M}+2 Z_{V M, V M} M_{V M} C_{V M}^{2}+2 Z_{V M, M} M_{V M} C_{V M} C_{M}+Z_{V M, P C} M_{V M} C_{V M} S_{P C}
$$

\section{Simulation of surveillance data}

The defect structural development of surveillance test pieces obtained by changing the damage rate (from $1.5 \times 10^{-8} \mathrm{dpa} / \mathrm{s}$ to $1.3 \times 10^{-10} \mathrm{dpa} / \mathrm{s}$ ), the temperature (from $573 \mathrm{~K}$ to $561 \mathrm{~K}$ ), and the solute concentration (from $0.6 \mathrm{wt} \%$ to $0.68 \mathrm{wt} \%$ ) of the previous code [6] is shown in Fig. 1. The solute concentration of the surveillance pieces was taken as the sum of the concentrations of $\mathrm{Cu}$ and Ni. Both elements are responsible for the embrittlement enhancement of steels [10]. The interaction of Mn with interstitials is important because the Mn-dumbbell binding energy is on the order of $0.4 \mathrm{eV}$ [11-13]. But in the surveillance data of Genkai Unit 1, though the concentration of Mn was three times higher than that of $\mathrm{Ni}$, the precipitation of Mn was much lower than that of Ni [4], and we did not introduce the dumbbell motion of solute-interstitial pairs in our model.

The values of coefficients used are listed in Table 2 under the label "Previous". The simulation predicts correctly vacancy cluster dissolution above $10^{-2} \mathrm{dpa}$. The decrease of interstitials in the loops around $10^{-4} \mathrm{dpa}$ was caused by the evaporation of vacancies from solute-vacancy clusters [6]. The loop concentration, the number of interstitials in a loop, the precipitate concentration, and the number of solutes in a precipitate are shown in Fig. 2. Above $10^{-4} \mathrm{dpa}$, vacancies escape from solute-vacancy clusters, which become precipitates. In the same figure, the results of the third and fourth surveillance data are indicated by two large symbols. Loops are observed by transmission electron microscopy with the strain field of dislocations. It is possible to detect loops of $1.5 \mathrm{~nm}$ by diffraction contrast images. Therefore the existence of electron microscopically invisible clusters cannot be denied. But in our present study, the main purpose was to explain the defect structure observed in surveillance test pieces, and we did not consider the invisible clusters. The size and the concentration of loops are correctly simulated, but the size and the concentration of precipitates are far from the real data. This difference is mainly caused by the large number of alloying elements in A533B.

The precipitation of $\mathrm{Mn}$ and $\mathrm{Ni}$ in A533B is one of important issues to take into consideration. The segregation of $\mathrm{Mn}$ and $\mathrm{Ni}$ on loops has been suggested [14,15]. But the segregation also strongly depends on the concentration of $\mathrm{Cu}$. In low $\mathrm{Cu}$ A533B $(0.04 \mathrm{wt} \% \mathrm{Cu})$, the concentration of precipitates was $1 / 3$ of that of high $\mathrm{Cu}$ A533B (0.16 wt\% Cu) [16]. It means that the Cu plays an important role for the precipitation of $\mathrm{Mn}$ and $\mathrm{Ni}$ even in low $\mathrm{Cu}$ A533B. In the case of surveillance test pieces of Genkai Unit 1, the Cu concentration was $0.12 \mathrm{wt} \%$ and the most of precipitates were formed with $\mathrm{Cu}$ precipitates [4,5], and we did not introduce the segregation of $\mathrm{Mn}$ and $\mathrm{Ni}$ on loops in our model.

For simulating the damage evolution in A533B, the migration energy of point defects, binding energy, and coefficients that determine the reaction rate (mainly Zs) were changed. The new list of parameters is reported in Table 2 under the label "Present". Fig. 3 shows the result of the defect evolution in A533B surveillance pieces. Fig. 4 shows the comparison between the simulation and surveillance data. The predicted values, especially for the size and the concentration of precipitates, are closer to the real case. The saturation and the sudden decrease of total vacancies in the vacancy clusters (voids) and in the solute-vacancy clusters (precipitates) above $10^{-3}$ dpa in Fig. 3, and the shrinkage of interstitial type dislocation loops above $10^{-3}$ dpa in Fig. 4, were caused by the dissociation of vacancies from voids and precipitates, and the absorption of the vacancies by loops. At nearly the same time, the growth of precipitates finished.

Watanabe et al. pointed out that the addition of $\mathrm{Mn}$ in Fe increases the migration energy of interstitials and vacancies [17]. The increase of migration energy of point defects in the present simulation (Table 2) was due to $\mathrm{Mn}$. The void formation was mainly prevented by the low binding energy between the vacancies and 
the voids, or between vacancies and the solute-vacancy clusters. Other factors that impeded the void formation were the low reaction rate between two vacancies $\left(Z_{V, V}\right)$, and the large sink efficiency $\left(10^{-6}\right)$. High sink efficiency was introduced by considering a bainite structure. The low density of loops is caused by the low direct formation of interstitial clusters $\left(P_{I C}\right)$, small difference between the interstitial absorption and vacancy absorption of loops $\left(Z_{I, I C}-Z_{V, I C}\right)$, and high sink efficiency $(C s)$. The low density and the large precipitates were due to the low reaction rate between vacancies, solutes, vacancy-solute pairs and solute clusters (i.e., small values of $Z_{V, M}, Z_{V, V M}, Z_{V M, V M}$, and $Z_{V M, M}$ ), and large solute absorption rate for the solute-vacancy clusters (large $Z_{V M, P C}$ ).

\section{Damage rate dependence}

By using the same code of section 3, a high damage rate case (using an irradiation dose similar to the one available at the JMTR) was simulated. The results are shown in Fig. 5. The irradiation temperature and damage rate were $563 \mathrm{~K}$ and $3.3 \times 10^{-7} \mathrm{dpa} / \mathrm{s}$, respectively. At these conditions, A533B of low $\mathrm{Cu}$ concentration (Mn: 1.43, Ni: 0.65, Mo: 0.5, Si: 0.19, C: 0.19, Cr: 0.13, Cu: 0.04, P: 0.004, S: 0.001 wt\%) was irradiated at 0.061 dpa. Voids (concentration: $2.4 \times 10^{-9}$; total vacancies in voids: $2.8 \times 10^{6}$ ) were observed in a transmission electron micrograph and are shown in Fig. 6. In the JMTR irradiation condition (accelerated irradiation), no loops were observed after $0.2 \mathrm{dpa}$. There is a possibility that they are too small to be observed by transmission electron microscopy. Another plausible reason is that loops are too large to be observed as loops in thin foil transmission electron microscopy specimens (about $50 \mathrm{~nm}$ in thickness). As a large number of dislocations existed even before irradiation, we could not get any information about interstitial clusters.

Fig. 7 shows the comparison between measured and simulated concentrations of voids and the number of vacancies in a void. The JMTR data at 0.061 dpa are indicated by large symbols. The simulation was in good agreement with measurements. In this simulation, in addition to irradiation temperature and damage rate, the solute concentration was also changed (from $0.68 \mathrm{wt} \%$ to $0.23 \mathrm{wt} \%$ ), because the Cu concentration was $1 / 3$ of that in the surveillance pieces studied in section 3 . For this irradiation dose range, $\mathrm{Cu}$ plays an important role in the precipitation. Few clear precipitates were observed in the 3D atom probe measurement of the same specimen [16]. In the present simulation, as can be seen in Fig. 5, isolated solutes (red filled triangle) remain even at $1 \mathrm{dpa}$.

\section{Concluding remarks}

The reaction kinetic analysis using rate equations is a powerful technique to simulate long-term events. For an accurate simulation, however, a large number of rate equations are required, and the determination of the equation coefficients is not easy. In the present study, the reaction kinetic analysis of neutron-irradiated A533B was performed using only 11 rate equations, and simulations were performed for damaged structures under high and low damage rates in conditions. Some equation coefficients were too large (for example $\left.Z_{V M, P C}\right)$ or too small $\left(Z_{V, M}, Z_{V M, V M}\right.$ and $\left.Z_{V M, M}\right)$ for reproducing the experimental data because of the limited number of rate equations used, and the consequences of compensation of mechanisms that are not included. For example, the dumbbell motion of Mn-interstitial pairs and the existence of invisible clusters were not considered. The annihilation of clusters was not adequately introduced, and the nucleation rate was reduced to reproduce the measured concentration. These points should be improved in future.

\section{Acknowledgments}

This work includes the results of "Research and development on degradation prediction of structural materials in nuclear reactors based on microstructural damage mechanisms" entrusted to the Tohoku University by the Ministry of Education, Culture, Sports, Science, and Technology of Japan (MEXT). 


\section{References}

[1] E. D. Eason, G. R. Odette, R. K. Nanstad, T. Yamamoto, Oak Ridge National Laboratory, 2007, ORNL/TM-2006/530.

[2] N. Soneda, A. Nomoto, J. Eng. Gas Turbines Power, 132 (2010) 102918.

[3] Y. Nagai, T. Toyama, Y. Nishiyama, M. Suzuki, Z. Tang, M. Hasegawa, Appl. Phys. Let., 87 (2005) 261920.

[4] Hearing of opinions of aging technical evaluation, Nuclear and Industrial Safety Agency, Ministry of Economy, Trade and Industry, Japan, 2011-2012 (in Japanese).

[5] N. Soneda, K. Nakajima, K. Nishida, K. Dohi, CRIEPI Research Reports, Q12007, 2013 (in Japanese).

[6] T. Yoshiie, Q. Xu, K. Sato, Nucl. Inst. Meth. Phys. Res., B 303 (2013) 37.

[7] T. Yoshiie, Q. Xu, K. Sato, K. Kikuchi, M. Kawai, J. Nucl. Mater., 377 (2008) 132.

[8] N. Yoshida, M. Kiritani, Phys. J, Soc. Japan, 35 (1973) 1418.

[9] M. Kiritani , N. Yoshida, H. Takata, Y. Maehara, J. Phys. Soc. Japan, 38 (1975) 1677.

[10] G. R. Odette, G. E. Lucas, JOM, 53 (2001) 18.

[11] E. Vincent, C.S. Becquart, C. Domain, J. Nucl. Mater., 359 (2006) 227.

[12] L. Messina, Z. Chang, P. Olsson, Nuclear Instruments and Methods in Physics Research B 303 (2013) 28.

[13] L. Malerba, G.J. Ackland, C.S. Becquart, G. Bonny, C. Domain, S.L. Dudarev, C.-C. Fu, D. Hepburn, M.C. Marinica, P. Olsson, R.C. Pasianot, J.M. Raulot, F. Soisson, D. Terentyev, E. Vincent, F. Willaime, J. Nucl. Mater., 406 (2010) 7.

[14] M. K. Miller, P. Pareige, Materials Research Society Symposium Proceedings. 650 (2001) R6.1.1.

[15] E. Meslin, B. Radiguet, M. Loyer-Prost, Acta Mat., 61 (2013) 6246

[16] T. Takeuchi, A. Kuramoto, J. Kameda, T. Toyama, Y. Nagai, M. Hasegawa, T. Ohkubo, T. Yoshiie, Y. Nishiyama, K. Onizawa, J. Nucl. Mater., 402 (2010) 93.

[17] H. Watanabe, S. Masaki, S. Masubuchi, N. Yoshida, K. Dohi, J. Nucl. Mater., 439 (2013) 268.

Table 1 Surveillance data from the Genkai Unit 1, Kyushu Electric Co., Inc. [4,5].

\begin{tabular}{clllll}
\hline Surveillance & Irradiation dose & \multicolumn{2}{c}{ Loops } & \multicolumn{2}{c}{ Precipitates } \\
\cline { 3 - 5 } number & \multicolumn{1}{c}{$(\mathrm{E}>1 \mathrm{MeV})$} & \multicolumn{1}{c}{ Concentration } & Diameter & Concentration & Diameter \\
\hline 3 & $3.5 \times 10^{19} \mathrm{n} / \mathrm{cm}^{2}$ & $6.6 \times 10^{20} \mathrm{~m}^{-3}$ & $2.7 \mathrm{~nm}$ & $2.3 \times 10^{23} \mathrm{~m}^{-3}$ & $3.0 \mathrm{~nm}$ \\
4 & $6.5 \times 10^{19}$ & $1.6 \times 10^{21}$ & 3.2 & $2.5 \times 10^{23}$ & 3.3 \\
\hline
\end{tabular}

Table 2 Coefficients used in the simulation and their respective values. "Previous" corresponds to the values used in [6].

\begin{tabular}{lccccccccccccccc}
\hline & $Z_{I, I}$ & $Z_{I, V}$ & $Z_{I, I C}$ & $Z_{I, V C}$ & $Z_{I, P C}$ & $Z_{V, V}$ & $Z_{V, V M}$ & $Z_{V, M}$ & $Z_{V, P C}$ & $Z_{V, I C}$ & $Z_{V, V C}$ & $Z_{V M, V M}$ & $Z_{V M, M}$ & $Z_{V M, I C}$ & $Z_{V M, V C}$ \\
\hline Previous & 10 & 10 & 44 & 1 & 1 & 10 & 10 & 10 & 1 & 40 & 1 & 10 & 10 & 40 & 1 \\
\hline Present & 40 & 40 & 41 & 24 & 1 & $10^{-2}$ & 1 & $10^{-4}$ & 1 & 40 & 40 & $10^{-3}$ & $10^{-3}$ & 40 & 1 \\
\hline
\end{tabular}

\begin{tabular}{lcccccccccccc}
\hline & $Z_{V M, P C}$ & $P_{I C}$ & $P_{V C}$ & $N_{I}$ & $N_{V}$ & $E_{I}$ & $E_{V}$ & $K_{V, M}$ & $K_{V, V C}$ & $K_{V, P C}$ & $M_{V M}$ & $C_{S}$ \\
\hline Previous & 1 & $10^{-5} P$ & $10^{-5} P$ & 2 & 2 & 0.15 & 0.57 & 0.1 & 1.0 & 1.59 & $0.01 M_{V}$ & $10^{-10}$ \\
\hline Present & 100 & $2 \times 10^{-7} P$ & $10^{-9} P$ & 2 & 2 & 0.3 & 1.0 & 0.1 & 0.9 & 0.9 & $0.01 M_{V}$ & $10^{-6}$ \\
\hline
\end{tabular}




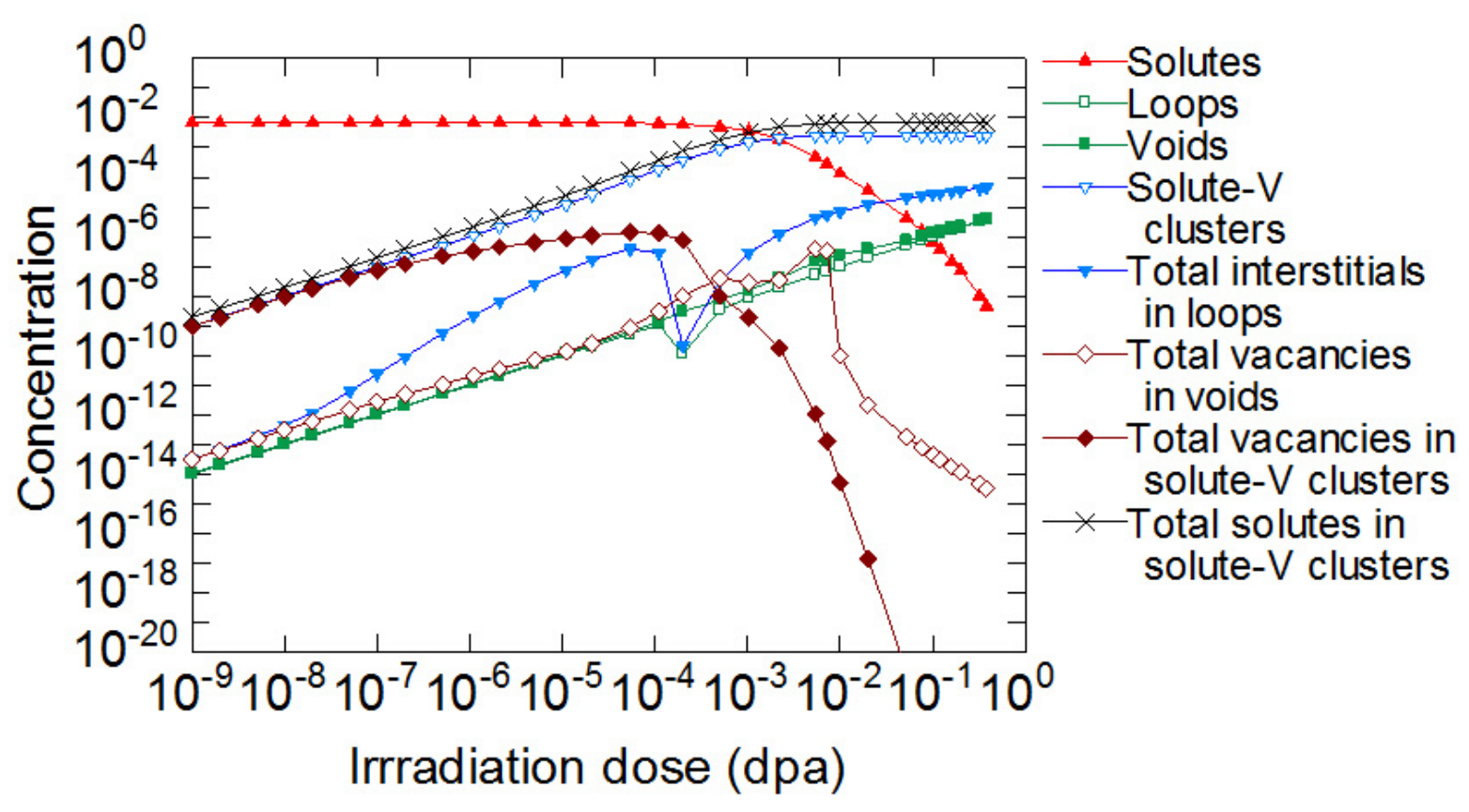

Fig. 1 The irradiation dose dependence of the concentrations of solutes, point defect clusters, solutes in solute-vacancy clusters, and vacancies in solute-vacancy clusters, under a damage rate of $1.3 \times 10^{-10} \mathrm{dpa} / \mathrm{s}$ at $561 \mathrm{~K}$ with the "Previous" rate equation coefficients listed in Table 2.

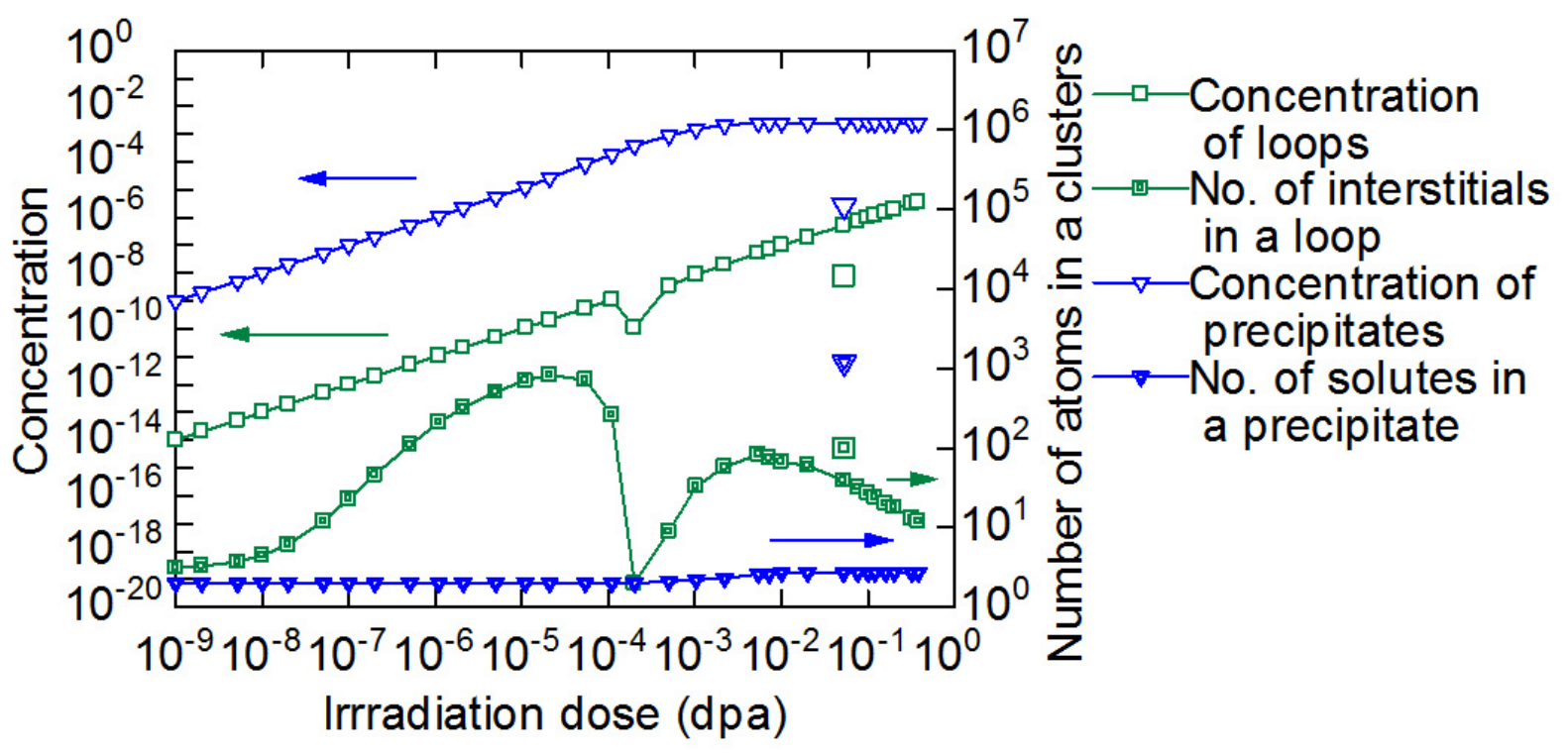

Fig. 2 The irradiation dose dependence of the concentrations of loops and precipitates (solute-vacancy clusters) and the number of interstitials in a loop and solutes in a precipitate under a damage rate of $1.3 \times 10^{-10}$ $\mathrm{dpa} / \mathrm{s}$ at $561 \mathrm{~K}$ with the "Previous" rate equation coefficients listed in Table 2. Surveillance data are indicated by the large symbols. 


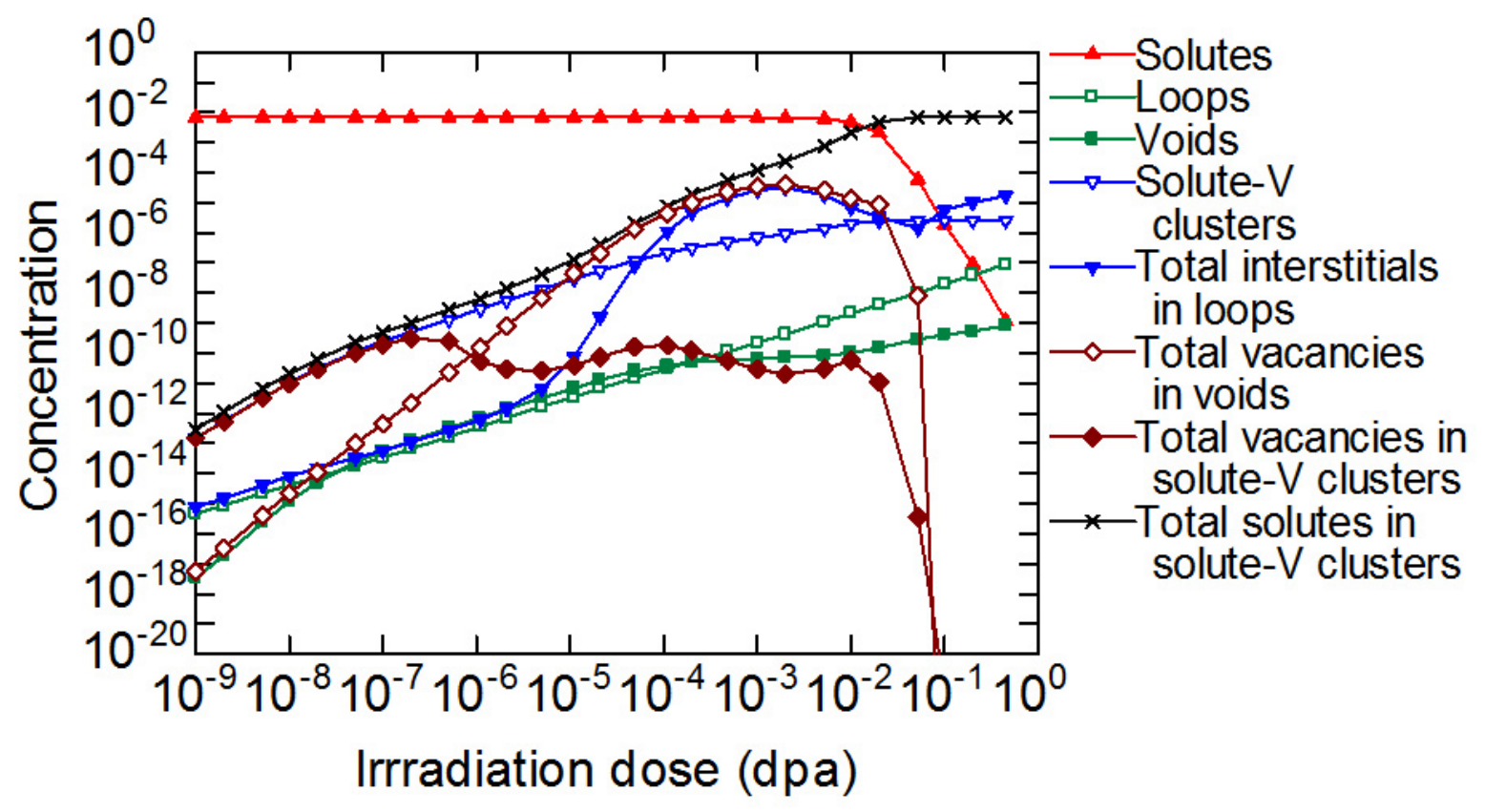

Fig. 3 The irradiation dose dependence of the concentrations of solutes, point defect clusters, solutes in solute-vacancy clusters, and vacancies in solute-vacancy clusters under a damage rate of $1.3 \times 10^{-10} \mathrm{dpa} / \mathrm{s}$ at $561 \mathrm{~K}$ with the "Present" rate equation coefficients listed in Table 2.

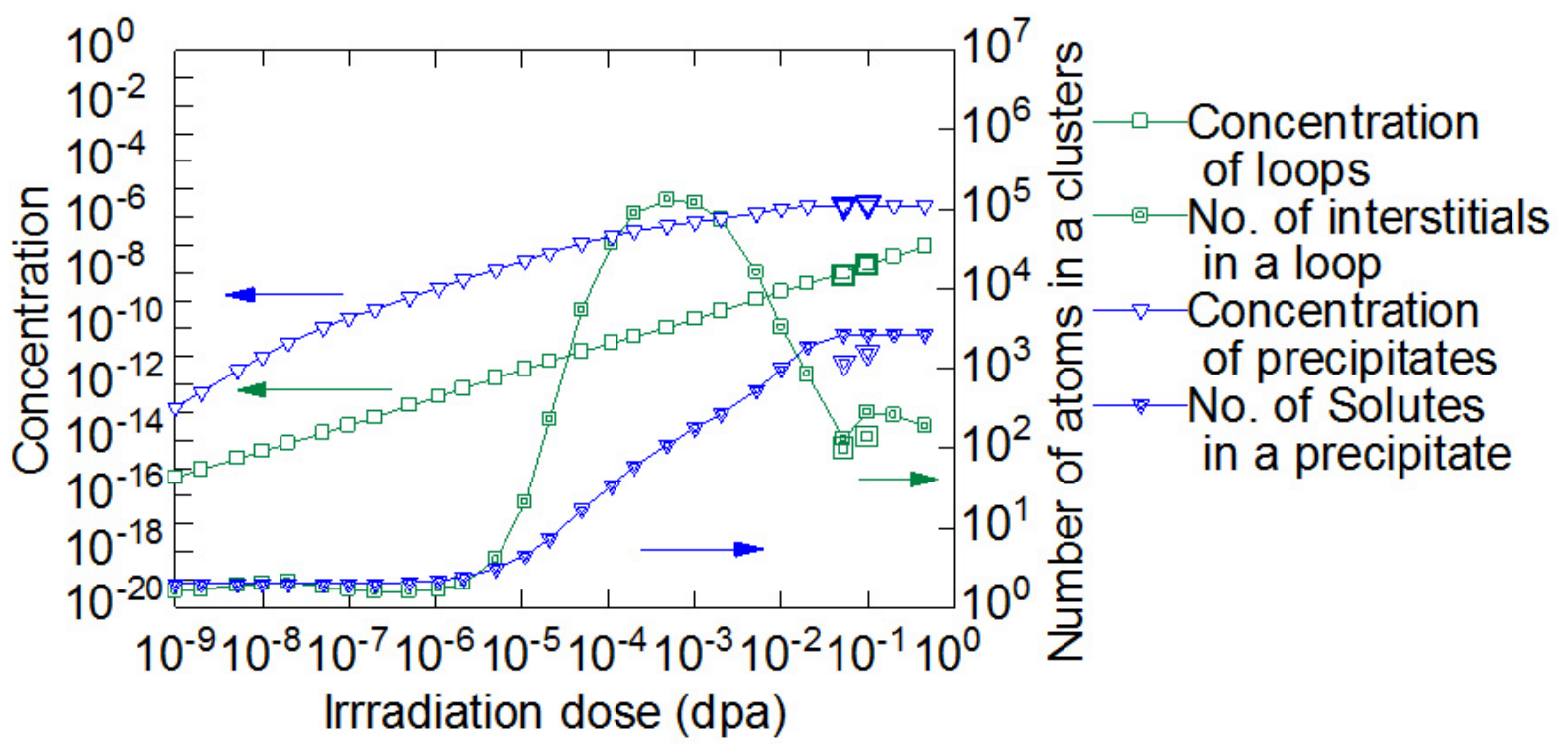

Fig. 4 The irradiation dose dependence of the concentrations of loops and precipitates (solute-vacancy clusters) and the number of interstitials in a loop and solutes in a precipitate under a damage rate of $1.3 \times 10^{-10}$ $\mathrm{dpa} / \mathrm{s}$ at $561 \mathrm{~K}$ with the "Present" rate equation coefficients listed in Table 2. Large symbols correspond to real surveillance data. 


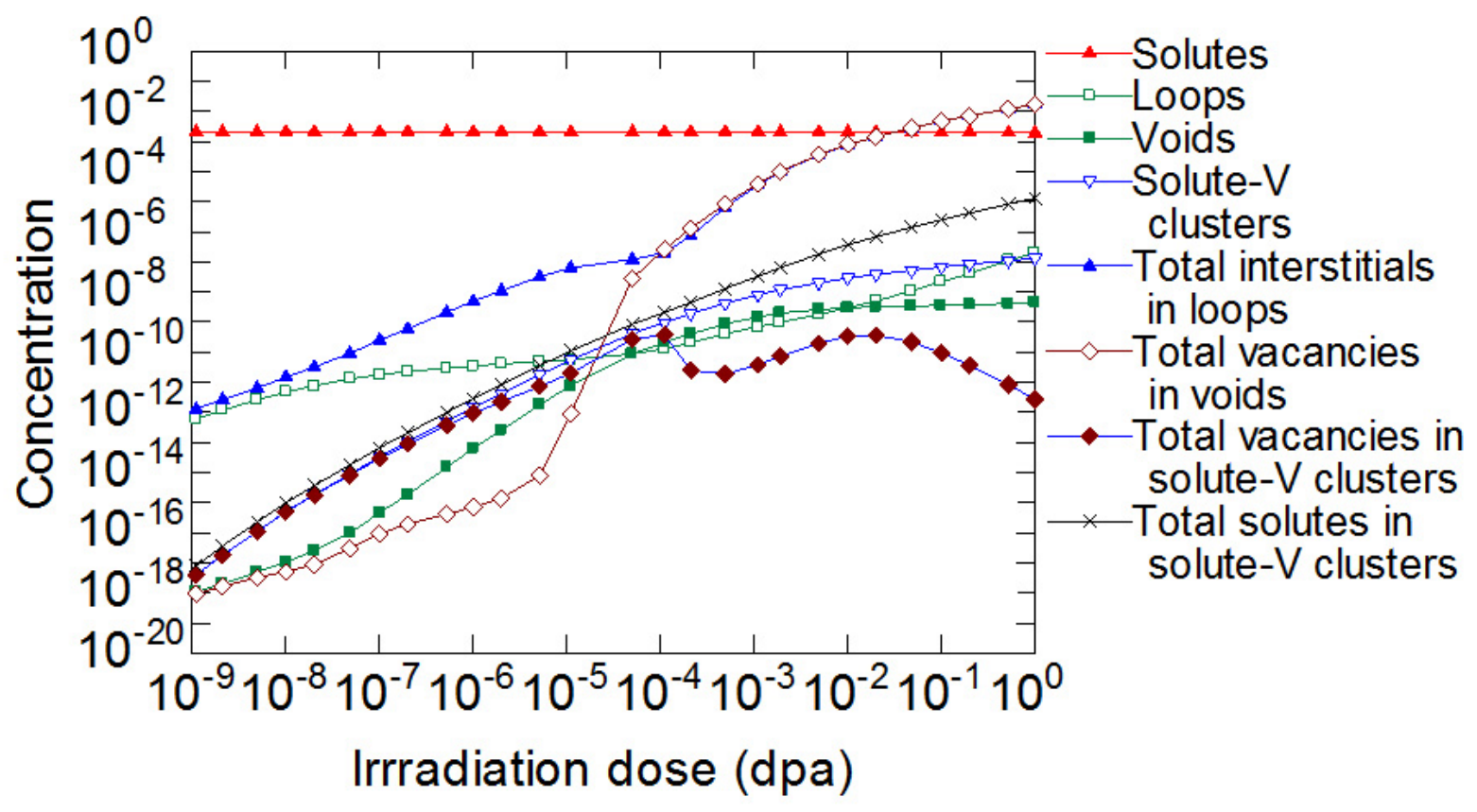

Fig. 5 The irradiation dose dependence of the concentrations of solutes, point defect clusters, solutes in solute-vacancy clusters, and vacancies in solute-vacancy clusters under a damage rate of $3.3 \times 10^{-7} \mathrm{dpa} / \mathrm{s}$ at $563 \mathrm{~K}$ with the "Present" rate equation coefficients listed in Table 2.

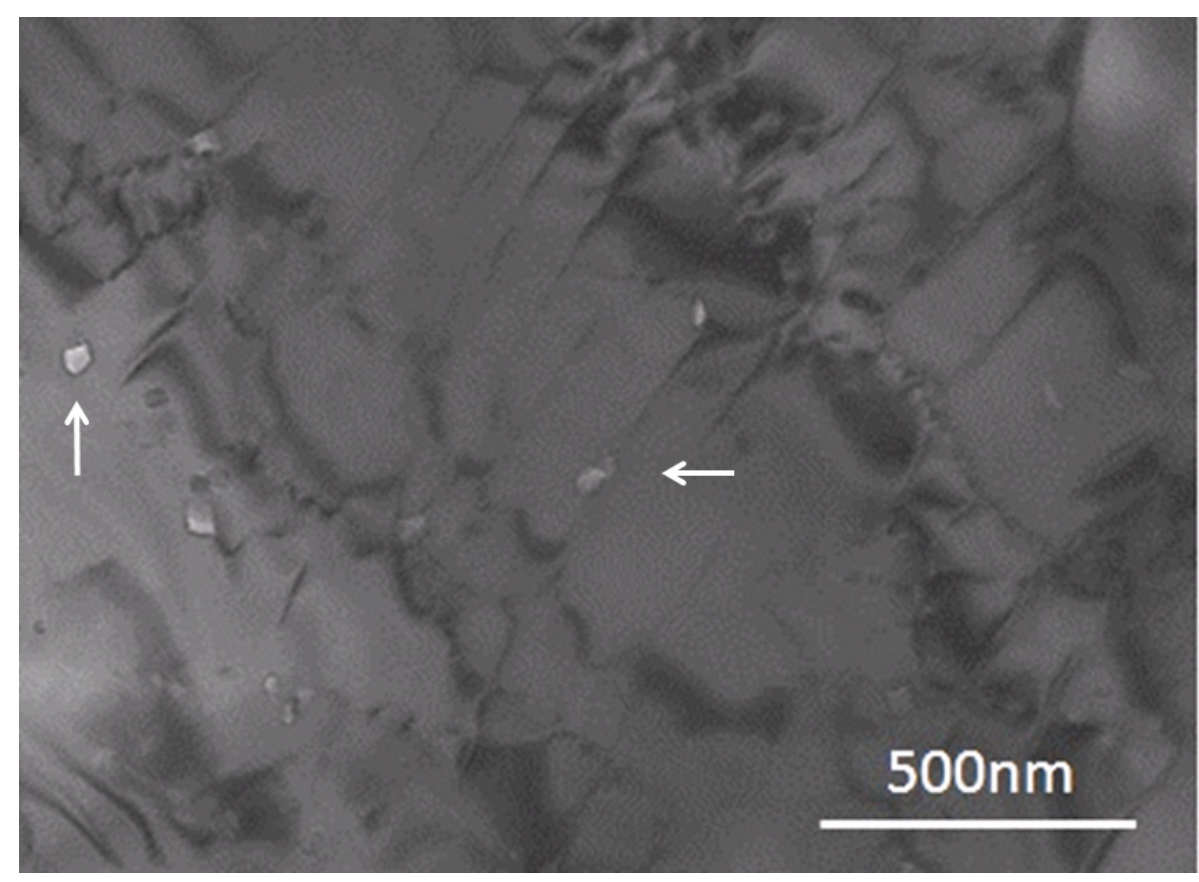

Fig. 6 Low-Cu A533B irradiated by the JMTR with a damage rate of $3.3 \times 10^{-7} \mathrm{dpa} / \mathrm{s}$ to $0.061 \mathrm{dpa}$. The clusters indicated by arrows are voids. 


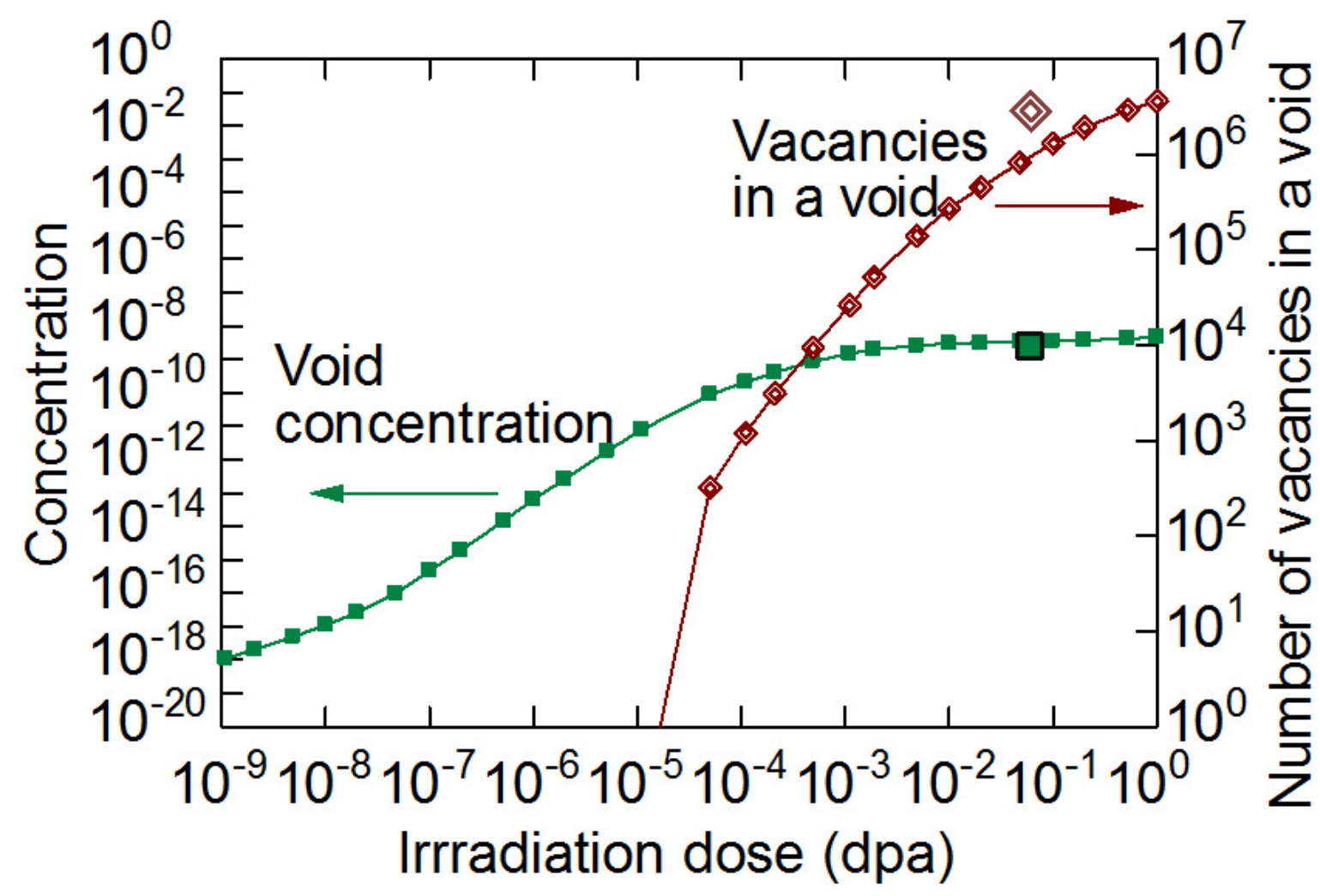

Fig. 7 The irradiation dose dependence of the concentrations of voids and the number of vacancies in a void under a damage rate of $3.3 \times 10^{-7} \mathrm{dpa} / \mathrm{s}$ at $563 \mathrm{~K}$ with the "Present" rate equation coefficients listed in Table 2. Large symbols correspond to experimental data by the JMTR. 